\title{
The cellular structure of bronchial carcinoids
}

\author{
Charles Marks \\ M.D., M.S., Ph.D., F.R.C.P., F.R.C.S., F.A.C.S. \\ J. LAMBERTY \\ M.D. \\ Department of Surgery, L.S.U. Medical School, Charity Hospital and \\ Veterans Administration Hospital, New Orleans
}

\begin{abstract}
Summary
A histological and electronmicroscopic study of bronchial carcinoids indicated that these tumours are argyrophilic in keeping with their occurrence in tissue of embryologically foregut origin. Normal bronchi contain cells that resemble, in their electronmicroscopic content, intestinal Kultschitzky-type cells.

Characteristic of the carcinoid cell is the presence of intracellular neurosecretory granules seen on electronmicroscopy despite the apparent absence of argentaffin granules under light microscopy.
\end{abstract}

\section{Introduction}

Reisner (1928) and subsequently Kramer (1930) suggested that bronchial adenomas arose from the ductal epithelium of bronchial glands. Churchill (1937) as well as Womack and Graham (1938) considered their origin to be from residual embryonic pulmonary tissue derived from entodermal and mesodermal elements. They explained the resemblance of the muco-epidermoid variety of bronchial adenoma to mixed salivary gland tumours on this basis. At this time, they suggested that bronchial adenomas be considered malignant.

Willis (1940) postulated the probability that these tumours arose from the mucous and mixed glands of the bronchial mucosa. Felton, Liebow and Lindskog (1953) held the view that the central and peripheral varieties of bronchial adenomas had different origins. Although they concurred that proximal lesions arose from mucous glands, they believed that the peripheral tumours arose from the lining of the epithelium. The controversy that had been extant regarding the origin and natural history of bronchial adenomas needs to be viewed in the light that clear distinction must be made between the carcinoid type, the cylindromatous variety, and the muco-epidermoid tumour. The cylindroma also known as an adenoid cystic carcinoma is the most malignant of the three types, arising as it does from the basal or surface epithelium of the bronchial ducts. The term bronchial adenoma, therefore, refers to three and possibly more distinct neoplasms that differ structurally as well as providing variations in their natural history.

\section{Material and methods}

During the period 1948-1973, twenty-eight patients with bronchial adenomas were diagnosed at Charity Hospital and Veterans Administration Hospital in New Orleans. The pathological classification of the adenomas were: twenty-four $(86 \%)$ carcinoid type, three $(11 \%)$ cylindroid, one $(3 \%)$ muco-epidermoid tumour. A pathological study of the twenty-four patients with carcinoid bronchial tumours provided this basis for histological and electronmicroscopic study of the carcinoid cell. Light microscopic studies were carried out after staining the sections with haematoxylin and eosin. Tissue for electronmicroscopic study was fixed in $4 \%$ glutaraldehyde and treated with $1 \%$ aqueous osmium tetroxide. After dehydration by passage through a series of alcohol it was embedded in Epon 812. Sections were appropriately cut, stained with lead citrate and uranyl acetate and prepared for examination.

\section{Results}

The bronchial carcinoid is a smooth, globoid tumour that protrudes into a proximal bronchus with its partial or complete occlusion (Fig. 1). Bronchoscopic examination generally discloses an intact mucous membrane without ulceration. Although the lesion is endobronchial it generally extends beyond the bronchus and the extrabronchial component may be large, even if the endobronchial component is quite small. The cut surface of the neoplasm may vary from a pale pink, soft tumour to a tan-coloured lobulated firm lesion with its parenchymal surface covered by a connective tissue capsule.

In the more invasive or frankly malignant bronchial carcinoid the capsule is poorly defined. It is noteworthy that a desmoplastic fibrous reaction or tissue necrosis is unusual in contrast to the frequency of these features in carcinoids of the gastrointestinal tract.

The carcinoid cell is typically uniform and small with acidophilic cytoplasm demonstrable with haematoxylin and eosin stains. Although it is quite 


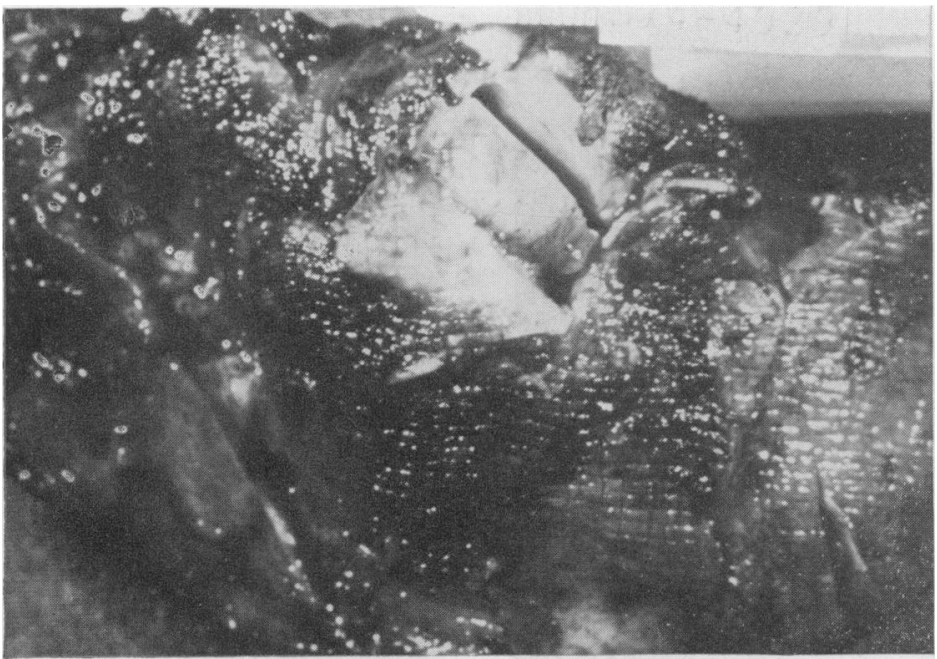

FIG. 1. Bronchial carcinoid tumour causing bronchial obstruction with atelectasis and bronchiectesis.

unusual to find nuclear mitoses or argentaffin granules, the nuclei contain finely stippled chromatin.

The cells are arranged in sheets, strands, or rounded masses resembling acini. The cell groups are situated about sinusoidal vascular spaces which may be so prominent as to suggest a haemangioma. This vascularity may lead to severe haemorrhage at bronchoscopic attempts to remove the endobronchial component of the carcinoid.

Local invasiveness may be expressed by cellular permeation of the capsule or by perivascular and perineural extension (Fig. 2). Despite this connotation of malignant potential, these cases are nevertheless associated with prolonged survival. The presence of tumour cells within bronchial or paratracheal lymph nodes is not necessarily indicative of subsequent spread. Fragments of bone are occasionally noted as a result of metaplasia in portions of the isolated bronchial cartilages.

Occasionally bulky cells are seen with granular or striated cytoplasm with small nuclei which contain a network of coarse chromatin. These oncocytic cells may be interspersed with carcinoid or transitional cells.

Histological criteria cannot be used to differentiate between benign and malignant tumours. $A$ basis for decision of malignancy needs to consider the degree of local invasiveness, lymph node involvement, and metastases.

\section{Electronmicroscopy}

Carcinoid tumour cells demonstrate a variable

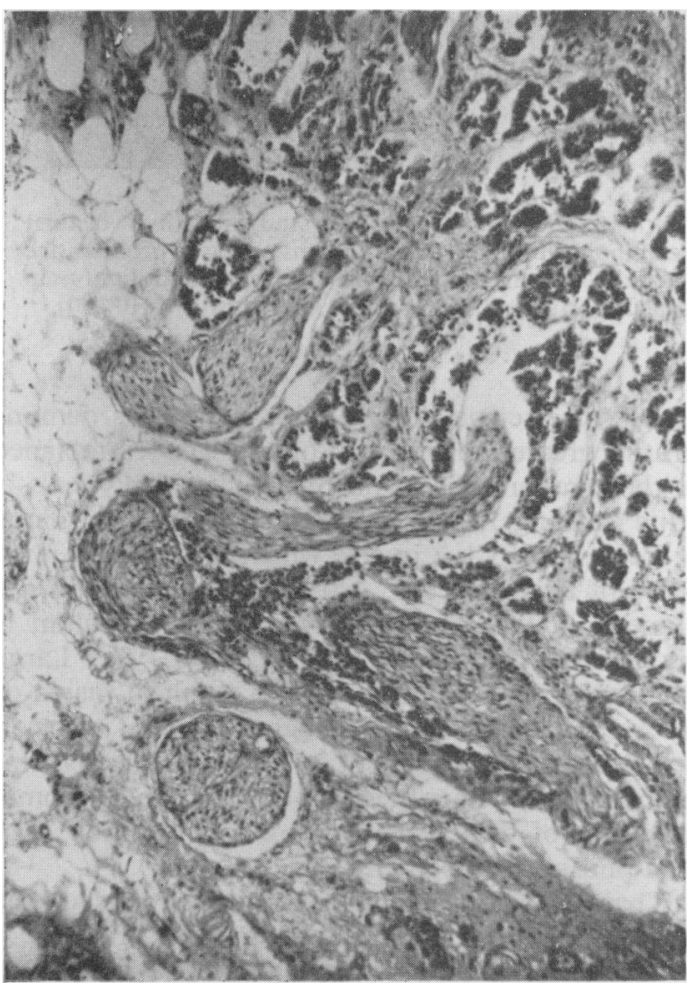

FIG. 2. Histological appearance of bronchial carcinoid tumour with perineural and lymphatic invasion $(\mathrm{H} \& \mathrm{E}$ $\times 90)$. 


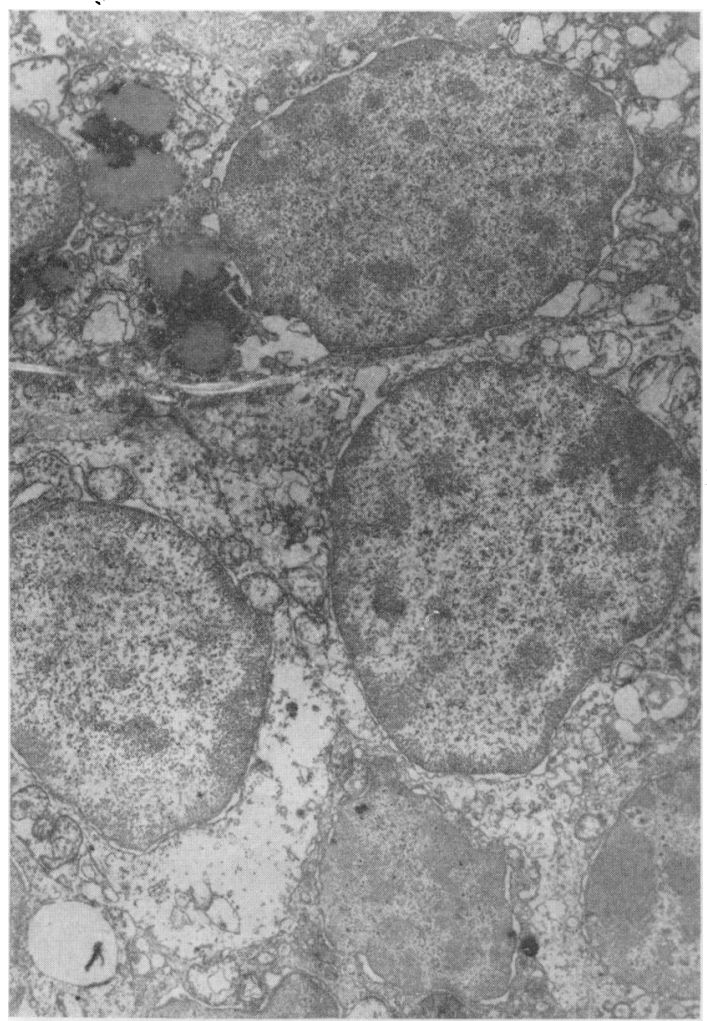

Fig. 3. Electronmicroscopic study of five distinct carcinoid tumour cells with intense nuclear proliferative activity. Electron dense granules surround lipofuscin vacuoles (uranyl acetate and lead citrate $\times 10200$ ).

degree of electron density with some cells demonstrating greater opacity than others. The resemblance of the tumour cells to normal Kultschitzky cells is quite striking. The carcinoid cells possess villous processes up to $1 \mu$ in size which interdigitate with those of adjacent cells. Although mitochondria are numerous, the smooth endoplasmic reticulum is scanty though well developed (Fig. 3). Large disternal spaces may be seen as a result of fusion of several smaller cisternae. Aggregations of electron dense bodies may be seen, bound by limiting membranes of the phagolysosomal type. The lysosomal character of these cells is confirmed by their high acid phosphatase content.

Characteristic of the carcinoid cell is the presence of intracellular neurosecretory granules, $100-500 \mu$ in diameter, scattered throughout the cytoplasm (Fig. 4). Many granules are found directly beneath the cell membrane and aggregations of the granules are often found in the vicinity of the Golgi apparatus. The granules are generally more numerous and

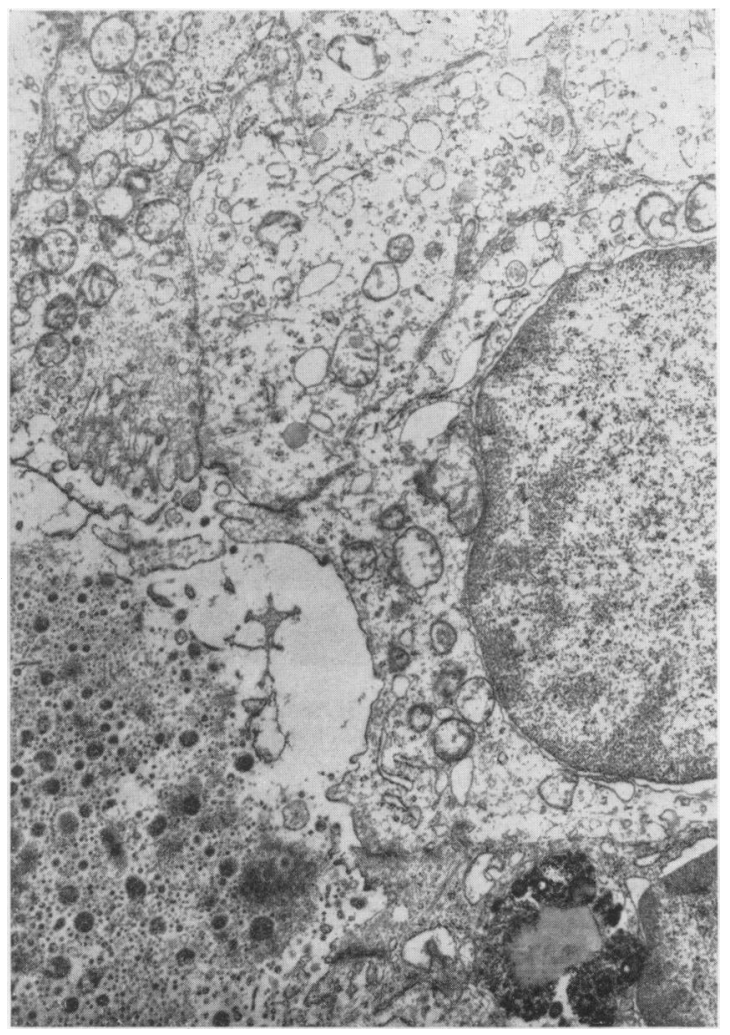

Fig. 4. Electronmicroscopic study of carcinoid tumour demonstrates the discrete arrangement of the electrondense secretory granules. Note the lipofuscin vacuole with surrounding granules (uranyl acetate and lead citrate $\times 20400$ ).

are more variable in size than in usual Kultschitzky cells.

The electronmicroscopic examination of bronchial carcinoids prepared by the Fontana silver impregnation technique of bulk fixed tissue demonstrates that the neurosecretory granules consist of dense aggregations of fine argentaffin granules. This is in contrast to the fact that under light microscopy most bronchial carcinoids do not contain demonstrable argentaffin granules, the majority of these cells being argyrophilic. This apparent anomaly may depend on the ability of the neurosecretory granules to store this secretion with variable ability to reduce silver compounds.

\section{Discussion}

Although most bronchial carcinoids fail to show argentaffin granules under light microscopy, most are argyrophilic. Williams and Sandler (1963) in classifying carcinoid tumours distinguished three 
carcinoid groups, based on differing embryological derivations associated with varying biochemical characteristics distinctive for each group: (1) foregut origin: bronchus, stomach, duodenum, biliary tract and pancreas; (2) midgut origin: arising from the mid-duodenum to mid-transverse colon: (3) hindgut origin: descending colon and rectum.

Although most bronchial carcinoids have a benign clinical course with prolonged survival, even in the absence of extirpative surgery, the tumour does on occasion transgress into normal restrictive barriers with local invasiveness, infiltration of lymph nodes and haematogenous spread.

When haematogenous spread does occur, the sites of predilection are liver, adrenals, brain and bones. Although bone metastases are rare, when they do occur, they are generally osteoblastic in nature. Pollard, Grainger and Fleming (1962) reported an unusual case of metastasizing bronchial adenoma associated with the carcinoid syndrome and noted the presence of numerous osteoblastic lesions. Toomey and Felson (1960) noted the similarity of the osteoblastic patterns of metastatic carcinoid lesions resulting from primary tumours in both the gastrointestinal tract and the bronchial tree. In a cumulative review of seventeen cases of bone metastases from carcinoid tumours, the lesions were noted to be blastic in fourteen cases, mixed blastic and lytic in two, and purely lytic in only one case.

The infrequency of associated concomitant or synchronous malignant disease in bronchial carcinoid may be contrasted with the frequent coexistence of evident adenocarcinoma in patients with carcinoids of the gastrointestinal tract.

Bensch et al. (1968) first demonstrated Kultschitzky-type cells in normal bronchi. Their ultrastructural electron microscopic study demonstrated cells in normal human bronchial mucosa that resembled the intestinal argentaffin cells. Gmelich, Benson and Liebow (1967) demonstrated that these cells were incorporated between exocrine cells situated within the limiting basement membrane and could be identified by their containing small dark cytoplasmic granules. Similar cells were also found between the columnar cells lining the peripheral bronchioles. It is these Kultschitzky-type cells that probably provide origin for the peripheral carcinoid tumour. The cells are particularly prominent in the larger bronchi, especially at sites of bronchial bifurcation. The argentaffin cell was originally thought to be derived from entoderm, but is now generally accepted to have a neuroectodermal origin. These cells are probably derived from the neural crest and migrate to the components of the foregut, represented by bronchus, stomach, biliary tract, pancreas, and proximal half of the duodenum; the midgut represented by the intestine, from the mid-duodenum to the mid-transverse colon, and the hindgut represented by descending colon and rectum. The migration commences in the 12-week fetus, and occurs long before these cells mature to develop this silver reaction. The failure of some of these cells to develop the silver reaction may represent an expression of biological idiosyncrasy.

\section{References}

Bensch, K.G., Corrin, G., Pariente, R. \& Spencer, H. (1968) Oat cell carcinoma of the lung. Cancer, 22, 1163.

Churchill, E.D. (1937) Discussion of bronchial tumors of Jackson, C.L. and Konzelmann, F.W. Journal of Thoracic Surgery, 6, 335.

Felton, W.L., Liebow, A.A. \& Lindskog, G.E. (1953) Peripheral and multiple bronchial adenomas. Cancer, 6, 555.

Gmelich, J.T., Benson, K.G. \& Liebow, A.A. (1967) Cells of قै Kultschitzky type in bronchioles and their relation to the origin of peripheral carcinoid tumors. Laboratory Investigation, 17, 88.

Kramer, R. (1930) Adenoma of bronchus. Annals of Otclogy, Rhinology and Laryngology, 39, 689.

Pollard, A., Grainger, R.G. \& Fleming, O. (1962) An unusual case of metastasizing bronchial adenoma associated with the carcinoid syndrome. Lancet, ii, 1084.

REISNER, D. (1928) Intrabronchial polypoid adenoma. Archives of Surgery, 16, 1201.

ToOmey, F.B. \& FrLson, B. (1960) Osteoblastic bone metastasis in gastrointestinal and bronchial carcinoids. American Journal of Roentgenology, 83, 709.

Williams, E.D. \& SANDleR, M.N. (1963) The classification of carcinoid tumours. Lancet, i, 238.

Willis, R.A. (1940) Argentaffin carcinomata (carcinoids) of the small intestine. Medical Journal of Australia, 2, 400.

Womack, N.A. \& Graham, E.A. (1938) Mixed tumors of the lung: so-called bronchial or pulmonary adenomas. Archives of Pathology, 26, 165. 